\title{
nature
}

1 October 1998 Volume 395 Issue no 6701

\section{Bytes, fast and free}

In celebration of Nature's new website and its benefits for our personal subscribers.

M eet any science publisher, ask about electronic publishing, and - unless they know you well — witness self-restraint in action. They won't weep about copious red ink on their balance sheets. Nor will they tell you of the wee-small-hours-of-themorning worries they have that scientists might just gain the copyright on their material. They will be tight-lipped on the obstacles to finding a perfect customizable search engine; the difficulties in turning publication into a seamless electronic interaction between authors, editors, referees and readers; the challenge of serving libraries electronically without losing subscription revenues; and the frustrating reluctance of many authors to accept that a purely electronic publication is worth anything at all.

Gradually, these problems and obstacles of perception are being overcome, while the naivety of those who believed publishing companies have no more role to play is becoming ever more clear. Moreover, although no one could describe electronic publishing as anything like mature, its huge potential for flexible and prompt delivery at affordable prices worldwide, combined with hypertext linkage between journals, is still a siren call to providers and users everywhere.

Nature's own website (www.nature.com) has been in operation since March 1996, and is visited more than 300,000 times per week. But over recent months, users will have noticed an important development: the introduction, on a test basis, of the full content of Nature. This issue marks the launch of the next stage in our website development: a new design, new 'web-only' content, and the availability of the full contents of Nature to all personal subscribers free of any additional charge. All that they have to do is to register online, supplying their subscriber number.

As well as our full printed content, subscribers will have access to web-only additional features that include in-depth software reviews, carried out by active researchers, articles discussing the web as a medium of scientific communication, and moderated debates on topics that may be purely scientific, or which may encompass a broader scope.

But Nature's presence on the web is very much part of the development of the journal as a whole, rather than an adjunct to the printed version, and subscribers will benefit accordingly in a number of additional ways.

First, promptness in delivery. From 00.01 GMT every Thursday, the latest issue of Nature will now be available to subscribers no matter where in the world they are, or how efficient (or otherwise) their postal services. Second, interactivity: readers can adjust how they look at web pages, they can respond immediately to what they are reading, and we can quickly react to that response.

Third, the value of our scientific papers is considerably enhanced as well. Unlike any other journal, for example, direct links from references in Nature papers to publications across all disciplines are now available thanks to arrangements with both Medline and the Institute of Scientific Information; and very soon, NASA will be included as well. Additional content is more readily available: Nature has a policy of allowing authors to refer to pieces of Supplementary Information - text, audio and video - which are too large or impractical to be published in the printed journal, but which are made available by us on request. On Nature's website, such information will now be integrated into the electronic version of the paper.

We know that we have subscribers for whom Nature is not only their favourite journal, it is the best. For them, from today, the world's best scientific journal in print is also the world's best scientific journal on the web.

Philip Campbell (Editor), Christopher Surridge (Web Editor)

\section{Bridging economics and ecology}

Economists and ecologists are increasingly working together. Such cooperation is both desirable and necessary.

W

hat's the difference between economists and ecologists? According to one wag, economists think they are God's gift to the world, whereas ecologists think the world is God's gift to them.

This might seem to offer a poor start to a close working relationship - and, indeed, beyond this flippant answer there are many cultural differences between the two disciplines. The traditional gulf between the natural and social sciences is further widened in this case by a tendency towards opposite political leanings: the economics that is in the ascendant today is closely aligned with capitalism, yet rampant capitalism is often accused of being the enemy of the environment.

But the academic discipline of ecology is not the same as 'environmentalism', and economists are at pains to explain that the real purpose of their discipline is the efficient allocation of scarce resources - a description that is, sadly, becoming increasingly relevant to the Earth's environmental assets. There are even technical similarities between the two fields: for example, an ecologist's description of competition and cooperation between species has much in common with the treatment of the behaviour of companies in microeconomics.

Given the crucial importance of both fields, it is not so surprising that, as described elsewhere in this issue (Briefing, page 426; Commentary, page 433), ecologists and economists are working closely together on ways to value and preserve the natural environment. Thus at one level, much of the success of the Kyoto Protocol on climate change hinges on efforts to set up an efficient and effective system of greenhouse-gas emissions trading. At another, cooperation between ecologists and economists will be needed in a \$2.3 million United Nations project announced last week to assess the demand for water in African cities, and its impact on freshwater resources and aquatic ecosystems.

In the days when humans were a small perturbation on the face of the planet, economics had little more to say about natural ecosystems than it does today about sunshine. But today, a viable combination of economics and ecology is essential; for while natural science may be 